\title{
EXPERIMENTAL STUDY CONCERNING THE DISTRIBUTION OF GRANULAR PARTICLE SHAPE FROM A FILTER LAYER
}

\author{
OANA IRIMIA ${ }^{1 *}$, VALENTIN NEDEFF ${ }^{1}$, MIRELA PANAINTE LEHĂDUŞ ${ }^{1}$, \\ CLAUDIA TOMOZEI ${ }^{1}$
}

1 "Vasile Alecsandri" University of Bacau, Calea Marasesti 157, Bacau, 600115, Romania

\begin{abstract}
The shape of granular particle from a filter layer represent a determinant factor regarding the efficiency of filtration process. In order to adequately predict the efficiency of granular filters is necessary to know the distribution of granular particle shape from filter layer. This paper presents a small study - in terms of experimental results, but laborious - in terms of sample preparation, regarding the identification of distribution by shape classes of granular particles from a filter layer. For experimental determinations have been used perlite and anthracite - two granular filter materials. It has been analyzed in terms of particle shape 1,000 particles of perlite and 1,000 particles of anthracite taken randomly from each filter layer. It has been observed that spherical particles have an average distribution for two type filter materials.
\end{abstract}

Keywords: perlite, anthracite, water filtration, particle shape, water treatment

\section{INTRODUCTION}

The systems which involve interaction between liquid and solid granular particles are frequently encountered in practice, being widely used especially in industrial processes (chemical and biochemical industry, food industry, pharmaceutical industry, detergent industry, mining, water and wastewater treatment) [1-5].

One of the most common two-phase systems liquid - granular particles is represented by filter layer used in processes such as water or wastewater treatment $[6,7]$. The knowledge of the properties for granular particles which forming filter layer is essential in order to predict the behavior of the filter installations and their corresponding design [8-11].

The properties which characterize the filter layer are related to: nature, area and of filter layer, pore size, particle shape, hydrodynamic resistance, chemical resistance and mechanical strength [12]. It has been shown that among these properties, the shape of granular particle has a significant influence on the efficiency of filtration process [8, 10, 11]. Wakeman demonstrated in an experimental study that the shape of granular particle from a filter layer primarily affects the volume and surface area of the particles, and hence their specific surface and the rate of fluid flow through formed filter cakes [11]. The author has conducted an experimental study using granular particles with perfect form (cubic, rectangular, spherical, fibrous, cylindrical and flakey) [11].

Another experimental research conducted by Ţîrţoacă, performed on three types of granular filter materials (quartz sand, perlite and anthracite), also demonstrates the influence of granular particle shape in filtration process [13]. Has been shown that particles which have a form as close to spherical shape forming the filtering layers with the best retention capacity [13]. Studies regarding the influence of granular particle were conducted by other

\footnotetext{
* Corresponding author, email: oana.tartoaca@ub.ro

(C) 2016 Alma Mater Publishing House
} 
researchers as well: Antony et al., Boskovic et al., Conell et al, Gregorova et al., Lin et al and Mota et al. They have also shown that the efficiency of the filtering process is significantly influenced by particle shape of the filter layer [14-18]. It has been consisted that filters which uses particles with sharp shape have a low performance. Taking into consideration the research results presented above it is considered to optimization of filtering process is necessary to know the particle shape distribution of granular filter layers [14-19].

In order to achieve the experimental study has been chosen to carry out measurements for two types of particles which form the filter layer: perlite and anthracite. The determination of granular particle shape was achieved by manual measurements of particles and using Tri-Plot software [20, 21].

\section{EXPERIMENTAL PROCEDURE}

In order to determine the distribution of granular particle shape in the filter layer have been chosen two kinds of filter materials used in particular for water treatment and wastewater treatment: perlite and anthracite $[12,13,22]$.

Perlite is a filter material which is used in particular for the removal of suspended solids from the water, alternatively or in combination with diatomaceous. Perlite granules have colors which vary from white to gray. Anthracite is also filter layer used for eliminating suspended solids from water. Anthracite is used in open or closed filters, being optimal for filling bilayer systems (with quartz sand). Granules of anthracite are colored glossy black $[12,13,22]$.

The determinations were made for a number of 1,000 perlite particles and for 1,000 anthracite particles taken randomly from the filtering layer. The average diameter of research material (perlite / anthracite) was $1 \mathrm{~mm}$ [12].

To determine the granular particle shape was used the Tri-Plot software. This software is a spreadsheet in Microsoft @ Excel which automatically displays the granular particle shape (Figure 1) [12, 13, 22].

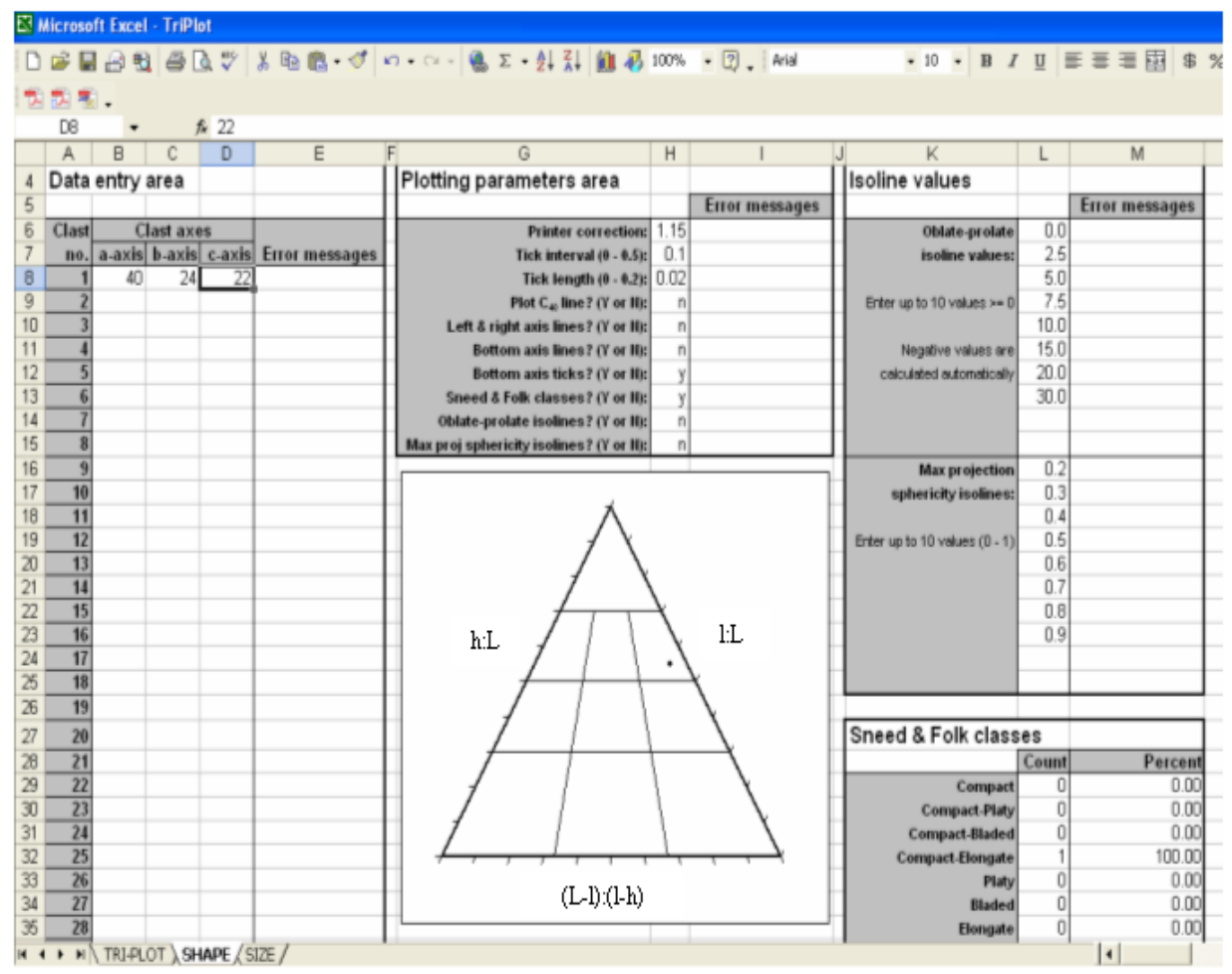

Fig. 1. The interface of spreadsheet Tri - Plot [13, 22].

Tri-Plot software is presented as a triangle diagram (Figure 2) that has at the base the ratio between the dimensional elements of the particles: length (a), width (b) and height (c). The available classes of shape (Figure 2) offered by the software are $[12,13,22]$ : 
- 1 - spherical;

- 2 - compact platy;

- 3 - compact blade;

- 4 - compact elongate;

- 5 - platy;

- 6 - bladed;

- 7 - elongate;

- 8 - very platy;

- 9 - very bladed;

- 10 - very elongate.

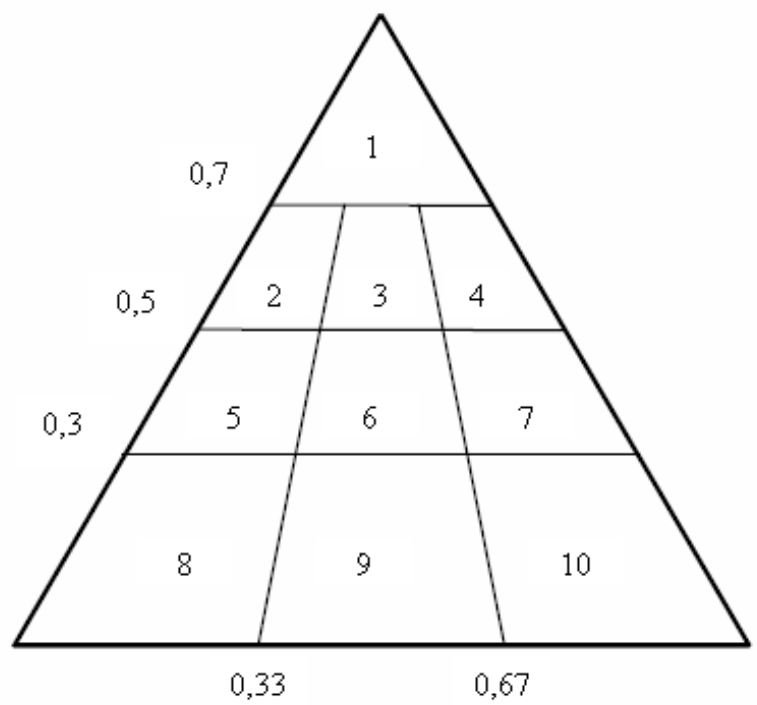

Fig. 2. Particle's shape classes [13, 22].

Thus, to identify the particle sizes, each granule of filter material was photographed twice (to view all three dimensions) using an electron microscope equipped with a webcam [12, 13, 22].

The image of particles was imported into Gimp software, program which allowed the recording of particle size values (Figure 3). Each particle size was introduced in Tri-Plot spreadsheet, which automatically shows the particle shape $[12,13,22]$.

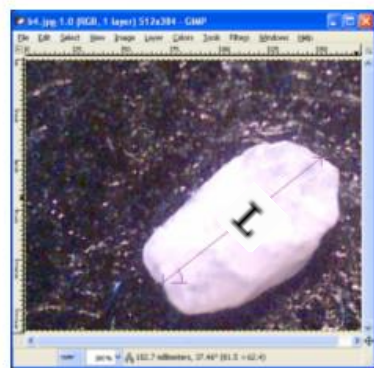

a.

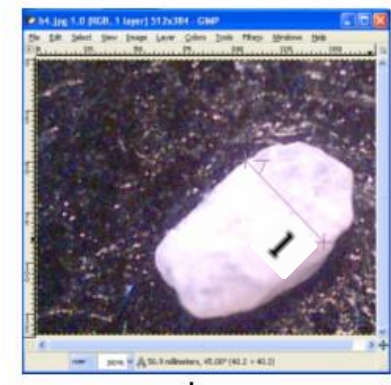

b.

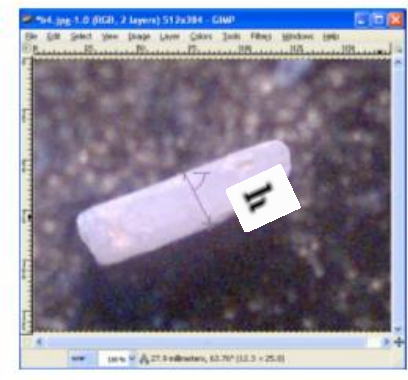

c.

Fig. 3. The task window of software Gimp [12, 13, 22]:

$\mathrm{a}$ - the image of particle's length; $\mathrm{b}$ - the image of particle's width; $\mathrm{c}-$ the image of particle's thickness.

\section{RESULTS AND DISCUSSION}

In order to know the distribution of the granular particle shape from the filter layers were carried out determinations for 1,000 perlite particles and for 1,000 anthracite particles. In Figures $4 \div 13$ are shown images 
with perlite and anthracite particles - an image representative for each class of form. In every image are highlighted and symbolized the three particle sizes: $\mathrm{L}$ - length of the particle; 1 - width of the particle; $\mathrm{h}$ - thickness of the particle [13, 22].

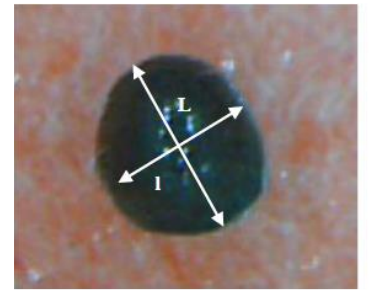

a. perlite

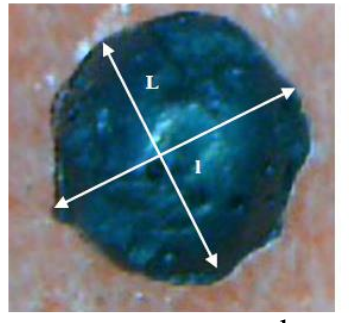

b. anthracite

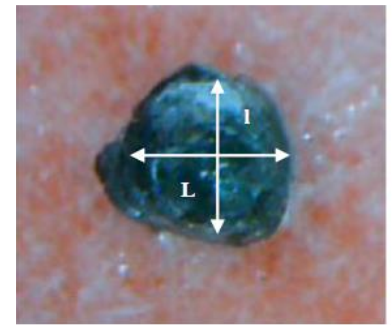

a. perlite

Fig. 4. The image of a spherical particle [13, 22].

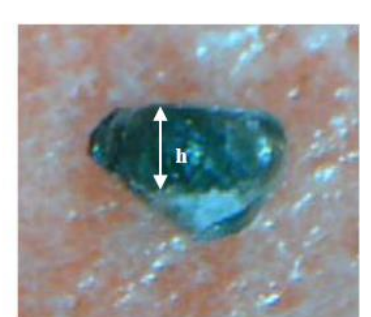

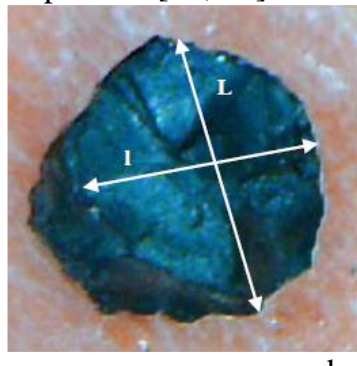

\section{b}

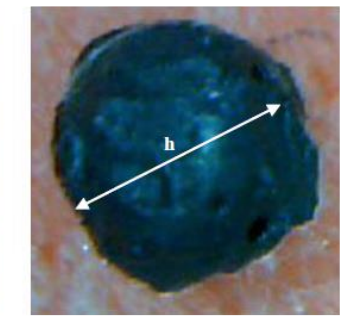

anthracite

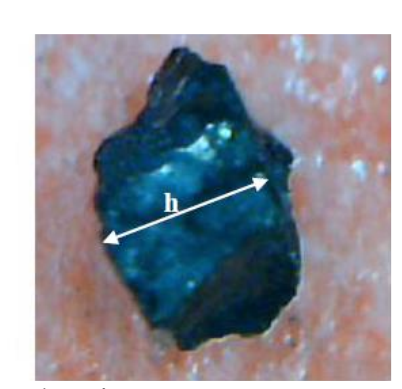

anthracite

Fig. 5. The image of a compact platy particle [13, 22]

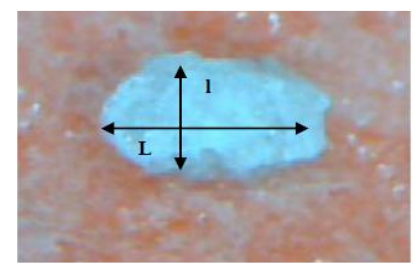

a. perlite

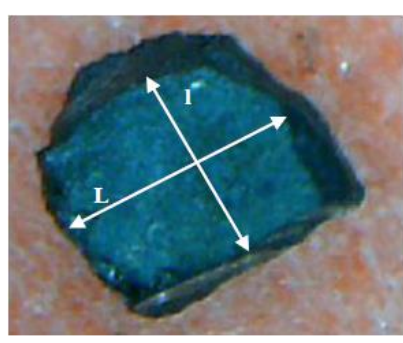

b. anthracite

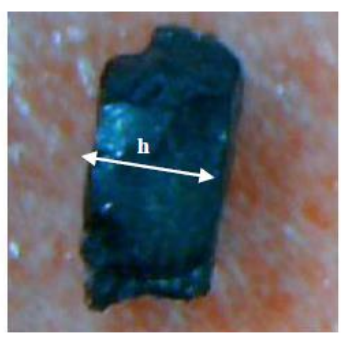

Fig. 6. The image of a compact blade particle [13, 22]

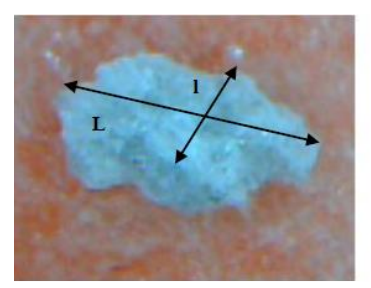

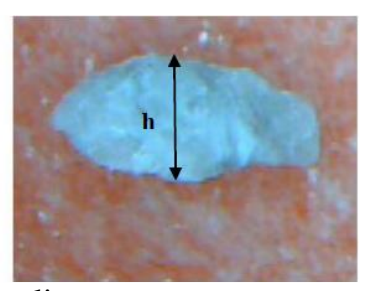

a. perlite

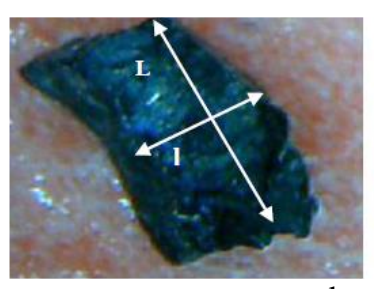

b. anthracite
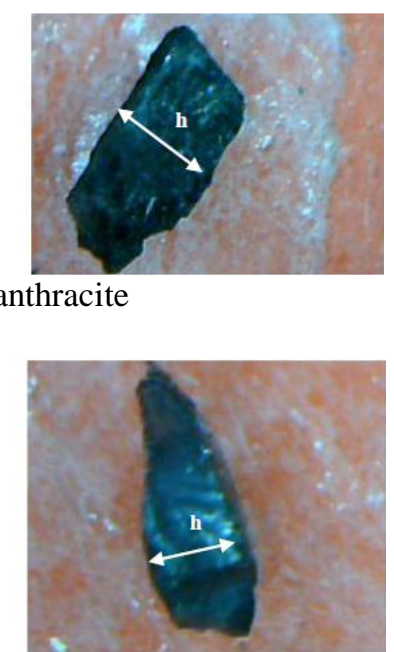

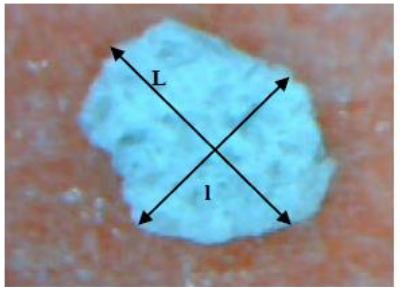

Fig. 7. The image of a compact elongate particle [13, 22]

a. perlite

b. anthracite

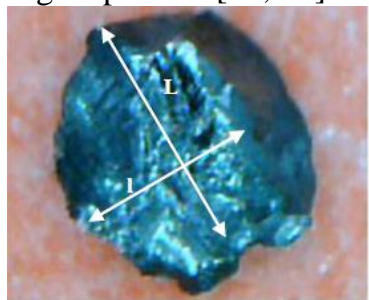

Fig. 8. The image of a platy particle $[13,22]$. 


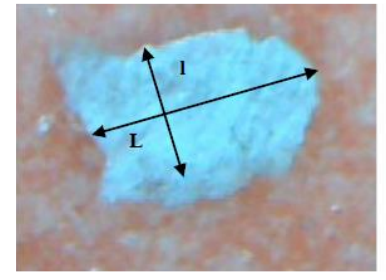

a. perlite

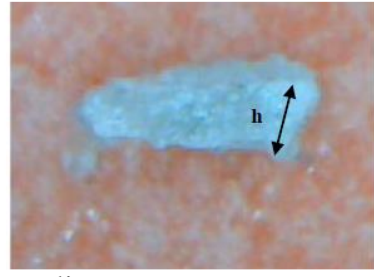

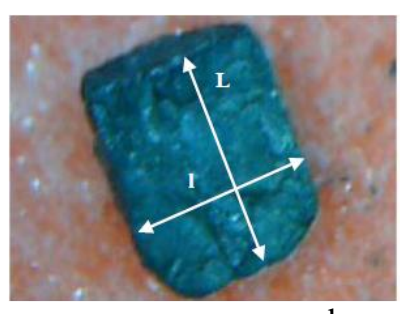

b. anthracite

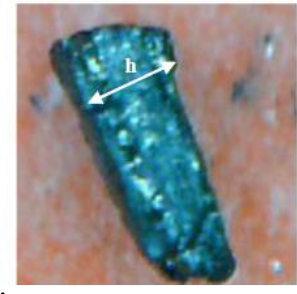

Fig. 9. The image of a bladed particle $[13,22]$.
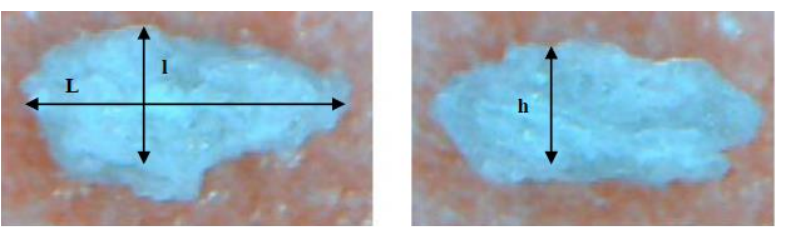

a. perlite
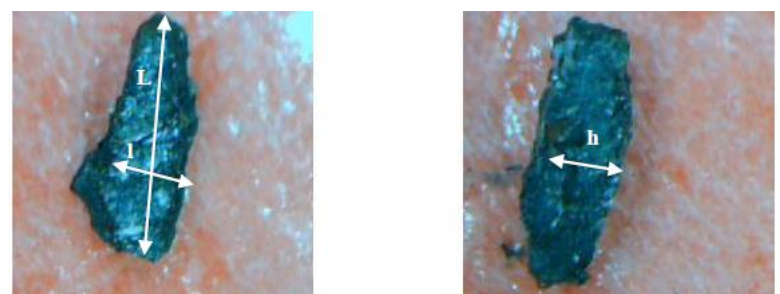

b. anthracite

Fig. 10. The image of a elongate particle [13, 22].
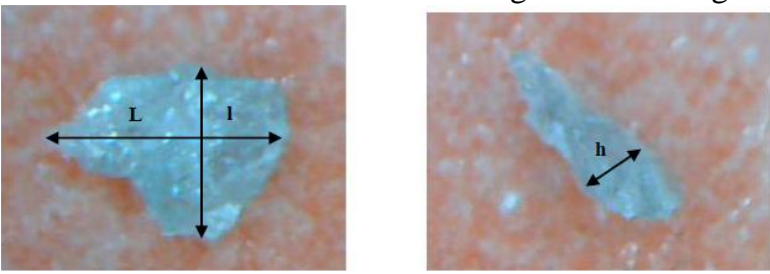

a. perlite
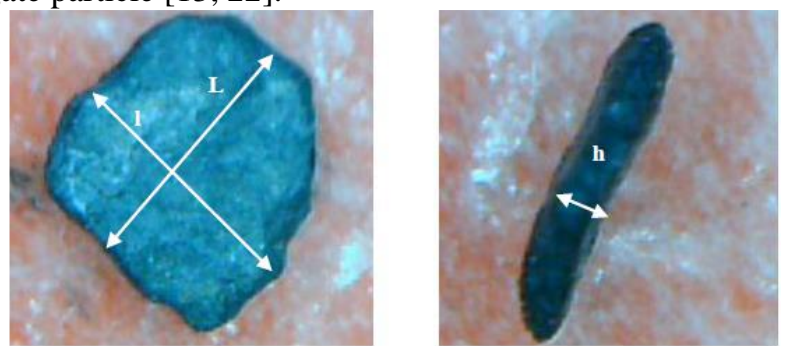

b. anthracite

Fig. 11 . The image of a very platy particle $[13,22]$.
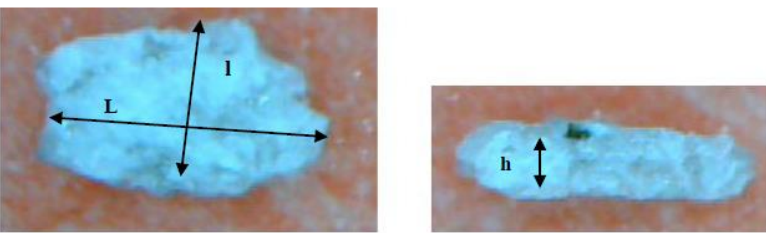

a. perlite
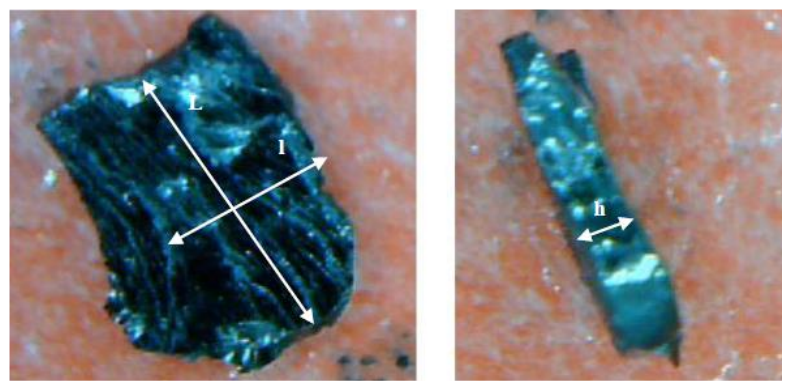

b. anthracite

Fig. 12. The image of a very bladed particle [13, 22].
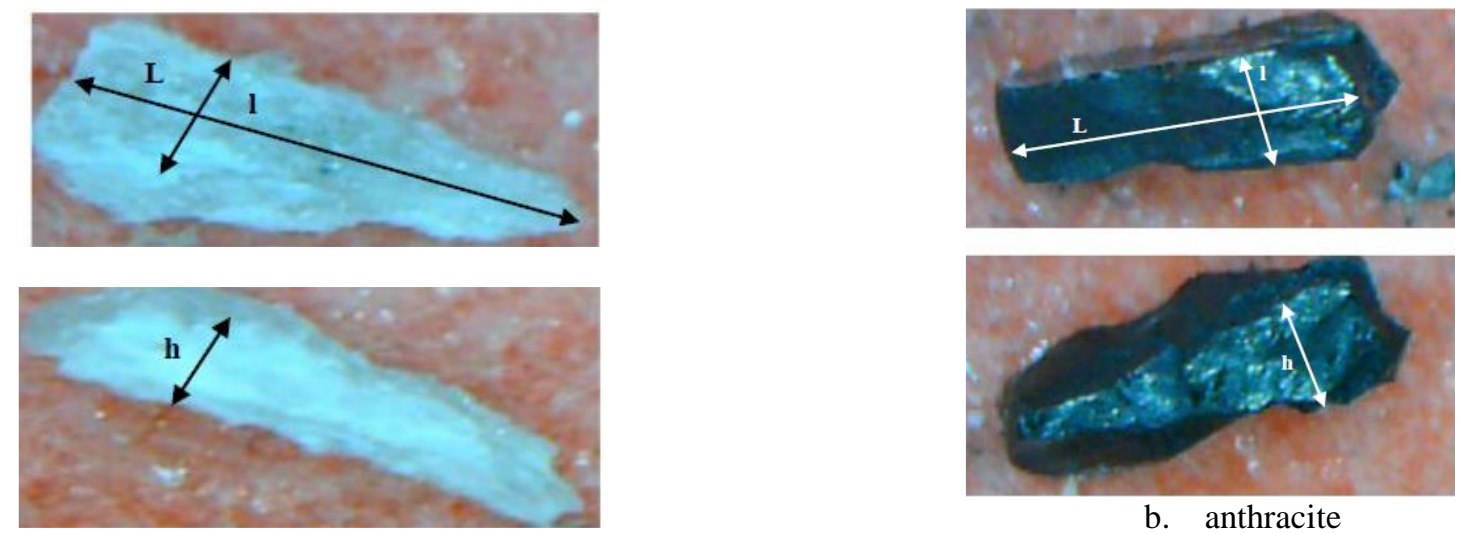

b. anthracite

a. perlite

Fig. 13. The image of a very elongate particle [13, 22]. 
After accomplishing the determinations was identified the distribution of the granular particle shape from the filter layer of perlite and from the filter layer of anthracite [13, 22].

In Figure 14 is represented graphically the weight on shape classes for 1,000 perlite particles. It is noticed that particles with compact platy, compact blade, compact elongate, platy, bladed and elongate shape prevails in the filter layer, having a relatively close distribution (values between $8.6 \%$ and $17.5 \%$ ). Particles with spherical shape - those with a high degree of retention (as previously shown in Introduction) have a relatively small distribution in the filter layer $(7.5 \%)$. It also notes that the particles with very platy, very blade and very elongate shape are in very small percentage in filter layer (values between $1.7 \%$ and $5.2 \%$ ) [13, 22].

The distribution on shape classes for 1,000 anthracite particles is represented graphically in Figure 15. In the case of this filter layer it is observed that particles with bladed shape have the greatest weight $-21.8 \%$. Particles with spherical, compact platy, compact blade, compact elongate, platy and elongate shape have a medium distribution, relatively close (values between $8.6 \%$ and $17.5 \%$ ). Particles with very platy, very blade and very elongate shape are in very small percentage (values between $2.3 \%$ and $5.4 \%$ ) [13, 22].

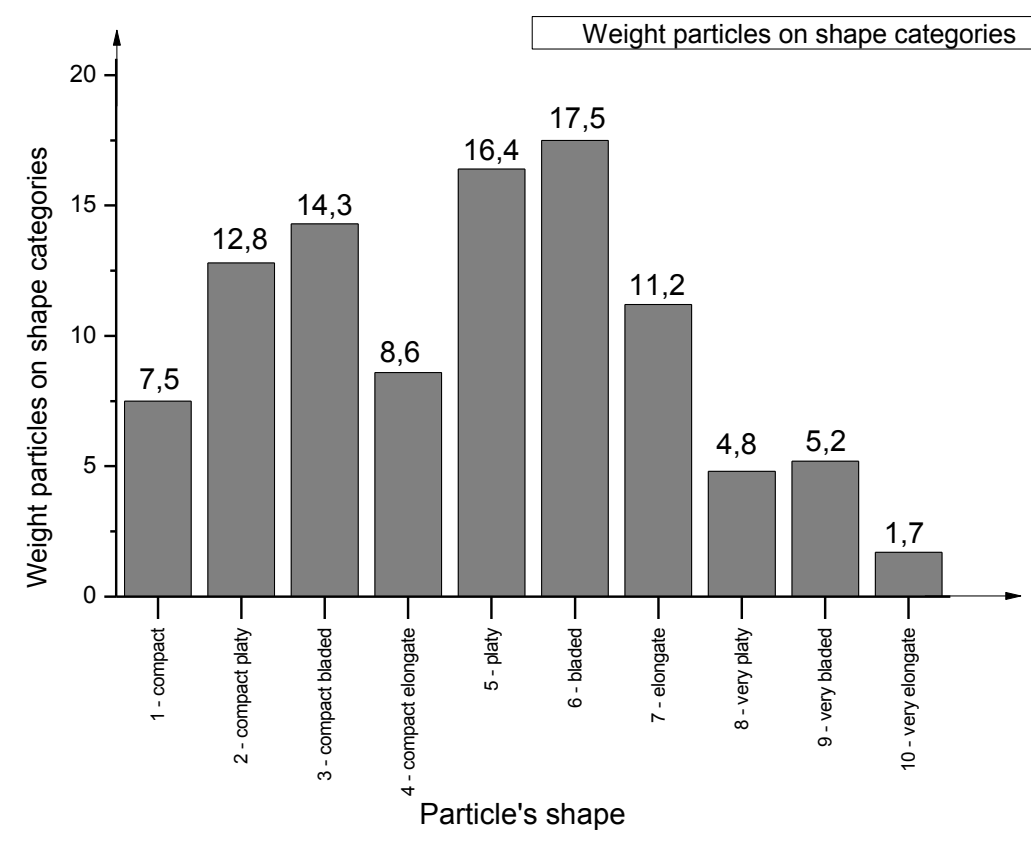

Fig. 14. The weight on shape classes for 1000 of perlite particles [13, 22].

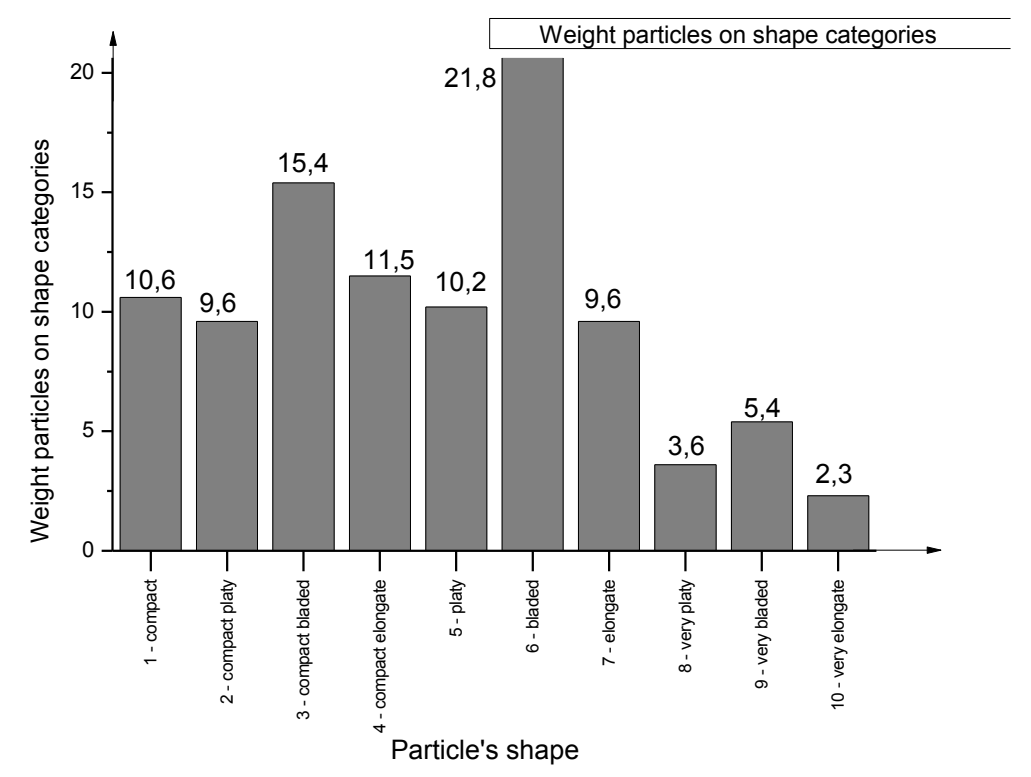

Fig. 15. The weight on shape classes for 1000 of anthracite particles [13, 22]. 


\section{CONCLUSIONS}

Researches in domain have shown that granular particle shape significantly affect the efficiency of filtration process. It was thus proved that the design and optimization of granular filters is closely related to particle shape that forming filter layer $[13,22]$.

In spite the importance of knowing the particle shape distribution of a granular filter layer, its determination is very difficult and requires a laborious work [13, 22].

Experimental study conducted for the two types of granular filter material - perlite and charcoal - shows that the particles with spherical shape have a medium distribution for both types of filter materials ( $7.5 \%$ in case of perlite and $10.6 \%$ in case of anthracite). It has also been found that, for both filter materials, particles with compact platy, compact blade, compact elongate, platy and elongate shape have a uniform distribution, with values between $8.6 \%$ and $16.4 \%$. As regards the particles with bladed shape, it is established that this particles prevails in both filter materials (17.5\% for perlite and $21.8 \%$ for anthracite) $[13,22]$.

Also, by comparing the two types of filter materials can state that in both filter layers, particles with sharp shapes (very platy, very blade and very elongate shape) are in very small percentage in filter layers (between 1.7 and $5.4 \%-$ values for both filter materials) [13, 22].

As it was presented in Chapter Introduction, researchers have demonstrated that the spherical particles should prevail in filter layer for a maximum efficiency of the filtration process. Against the background of these demonstrations, in order to optimize the filtration processes it is recommended a shape-sorting of particles that form granular filter layers $[13,22]$.

\section{REFERENCES}

[1] Aroninoa, R., Dlugy, C., Arkhangelsky, E., Shandalov, S., Oron, G., Brenner, A., Gitis, V., Removal of viruses from surface water and secondary effluents by sand filtration, Water Research, vol. 43, no. 1, 2009, p. 87-96.

[2] Huck D., Particle shape - an important parameter in pharmaceutical manufacturing. Application Specialist Vision Systems (http://www.chemeurope.com/en/whitepapers/61206/particle-shape-an-important-parameter-inpharmaceutical-manufacturing.html - 09.05.2014).

[3] Krumbein, W.C., Measurement and geological significance of shape and roundness of sedimentary particles, Journal of Sedimentary Research, vol. 11, no. 2, 1941, p. 64-72.

[4] Santamarina J.C., Cho G.C., Soil behaviour: The role of particle shape, Proc. Skempton Conference, London, 2004, (https://egel.kaust.edu.sa/PublishingImages/Particles\%20shape/cho_et_al_2006.pdf - 09.05.2014).

[5] Stan, L. C., Buzbuchi, N., Memet, F., Costs evaluation for ballast water treatment applying the advanced oxidation technology, Environmental Engineering and Management Journal, vol. 8, no. 6, 2009, p. 1385-1389.

[6] Purchas, D., Sutherland, K., Handbook of Filter Media, Publisher Elsevier Science \& Technology Books, 2002.

[7] Robescu, D.N., Robescu, D.L., Constantinescu, I., Szabolcs, L., Fluide polifazate, Editura Tehnică, Bucureşti, 2000.

[8] Boskovica, L., Altmanab, I.S., Agranovskia, I.E., Braddocka, R.D., Myojoc, T., Choib, M., Influence of particle shape on filtration processes, Aerosol Science and Technology, vol. 39, no. 12, 2009, p. 1184-1190.

[9] Cho, G.C., Dodds, J., Santamarina, C., Particle shape effects on packing density, stiffness and strength, Journal of Geotechnical and Geoenvironmental Engineering, vol. 132, no.5, 2006, p. 561-602.

[10] Wadell, H., Volume, shape and roundness of rock particles, The Journal of Geology, vol. 40, no. 5, 193, p. 443451.

[11] Wakeman, R., The influence of particle properties on filtration, Separation and Purification Technology, vol. 58, no. 2 , 2007, p. 234-241.

[12] Ţîrţoacă (Irimia), O., Nedeff, V., Lazăr, G., Panainte, M., Theoretical studies viewing the influence of particles' shape from filter layer in the mechanical filtration process, Journal of Engineering Studies and Research, vol. 17, no. 4, 2011, p. 40-45.

[13] Țîrţoacă (Irimia), O., Studies and researches on the possibilities to increase the quality of water for different types of uses, Ph.D. Thesis, "Vasile Alecsandri" University of Bacau, Romania, 2011.

[14] Antony, J., Kuhn, M.R., Influence of particle shape on granular contact signatures and shear strength: new insights from simulations, International Journal of Solids and Structures, vol. 41, 2004, p. 5863-5870.

[15] Boskovic, L., Influence of submicron particle shape on behavior during filtration and separation processes, Publisher Griffith University, 2008. 
[16] Conell, H., Zhu, J., Bassi, A., Effect of particle shape on crossflow filtration flux, Journal of Membrane Science, vol. 153, 1999, p. 121-139.

[17] Gregorová, E., Pabst, W., Bouchet, J.-B., Influence of particle shape on the viscosity of kaolin suspensions, Acta Geodyn. Geomater., vol. 6, 2009, p. 101-109.

[18] Lin, T., Chen, W., Wang, L., Particle properties in granular activated carbon filter during drinking water treatment, Journal of Environmental Sciences, vol. 22, 2010, p. 681-688.

[19] Mota, M., Teixera, J., Yelshin, A., Cortez, S., Effect of the particle shape on flow through porous media, vol. 1, 2005, p. 341-349.

[20] Graham, D., Tri-Plot - An Excel spreadsheet for the preparation of triangular (ternary) diagrams for particle shape and tri-variate data - Version 1.4., Department of Geography, Loughborough University, Publisher Leicestershire LE11 3TU UK., Loughboroug, 2006.

[21] Graham, D., Midgley, N., Graphical representation of particle shape using triangular diagrams: an excel spreadsheet method. Earth Surface Processes and Landforms, vol. 25, 2000, p. 1473-1477.

[22] Ţîrţoacă (Irimia), O., Nedeff, V., Panainte, M., Lazar. G., Potabilizarea apelor. Procedee si tehnici de filtrare, Editura Alma Mater, Bacau, 2014. 